\title{
Blood Pressure Variability after Intravenous Thrombolysis in Acute Stroke Does Not Predict Intracerebral Hemorrhage but Poor Outcome
}

\author{
Lars Kellert $^{\mathrm{a}}$ Marek Sykora ${ }^{\mathrm{a}, \mathrm{b}}$ Christoph Gumbinger ${ }^{\mathrm{a}}$ Oliver Herrmann ${ }^{\mathrm{a}}$ \\ Peter A. Ringleb ${ }^{a}$

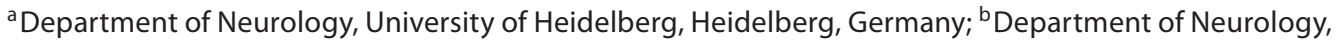 \\ Comenius University, Bratislava, Slovakia
}

\section{Key Words}

Stroke - Acute stroke $\cdot$ Blood pressure variability .

Intravenous thrombolysis $\cdot$ Intracerebral hemorrhage

\begin{abstract}
Background: The relevance of blood pressure variability (BPV) in the development of intracerebral hemorrhage (ICH) after intravenous thrombolysis (IVT) in acute stroke still remains uncertain. Methods: 427 consecutive patients treated with IVT in the years 2007-2009 were studied. Blood pressure (BP) values were analyzed from admission to follow-up imaging scan and described as mean, maximum, minimum, standard deviation (SD), difference between maximum and minimum, successive variation (SV) and maximum SV. $\mathrm{ICH}$ was categorized based on radiologic criteria and symptomatic ICH ( $\mathrm{sICH}$ ) was defined as ICH plus worsening of the $\mathrm{Na}$ tional Institute of Health Stroke Scale by $\geq 4$ points or leading to death. Three-month outcome was described by means of the modified Rankin Scale. Results: We observed any ICH in 51 (11.9\%) and sICH in 10 (2.3\%) patients. Systolic and diastolic BP profiles, including mean, maximum, minimum, SD, difference between maximum and minimum, SV and maximum SV, did not differ between ICH-negative, ICH-positive
\end{abstract}

and $\mathrm{sICH}$ patients. In univariate analysis, high systolic BPV was associated with $\mathrm{sICH}(p=0.03)$. A logistic regression model to predict ICH only found early CT findings $(\mathrm{OR}=2.74$, $95 \% \mathrm{Cl}=1.47-5.11, \mathrm{p}<0.01)$ as independently associated with $\mathrm{ICH}$. Poor 3-month outcome was independently predicted by age $(\mathrm{OR}=0.96,95 \% \mathrm{Cl}=0.94-0.97, \mathrm{p}<0.001)$, NIHSS on admission (OR $=0.84,95 \% \mathrm{Cl}=0.80-0.87, \mathrm{p}<0.001)$, $\mathrm{ICH}(\mathrm{OR}=0.29,95 \% \mathrm{Cl}=0.13-0.66, \mathrm{p}<0.01)$ and high systolic BPV $(\mathrm{OR}=1.68,95 \% \mathrm{Cl}=1.05-2.69, \mathrm{p}<0.05)$. Conclusions: We demonstrate that high $\mathrm{BPV}$ in patients receiving IVT leads to poor outcome but does not increase the risk of $\mathrm{ICH} / \mathrm{s} \mid \mathrm{CH}$.

Copyright $\odot 2011$ S. Karger AG, Basel

\section{Introduction}

After intravenous thrombolysis (IVT) in acute stroke, the development of hemorrhagic transformation (HT) and especially symptomatic intracerebral hemorrhage $(\mathrm{sICH})$ are some of the most feared adverse events. Several conditions are suggested to enhance the risk of HT/ sICH, including among others age [1], stroke severity presented by the National Institute of Health Stroke 
Scale (NIHSS) [2], congestive heart failure [1], early infarct signs [1,3], platelet count [4], serum glucose and diabetes [5], antithrombotics [1], time to treatment [6] and elevated systolic blood pressure (BP) $[1,7]$. Blood pressure variability (BPV) - the variation of BP with time - is presumed to be a strong and independent predictor of stroke in general, potentially more powerful than the absolute BP levels [8]. In addition, BPV was linked to stroke and development of HT and was demonstrated to be independently associated with outcome and with development of HT during the first 7 days after IVT $[9,10]$. Furthermore, BPV seems to contribute to growth of diffusion-weighted imaging lesions and deterioration of clinical course after IVT [11]. Most recently, a study demonstrated that BPV enhances the risk of HT within $72 \mathrm{~h}$ after acute cerebral infarction independently of treatment with IVT [12]. Besides, BPV was shown to influence short-term outcome after stroke by increasing the rate of death and neurologic deterioration at day 10 after stroke [13].

In the present study, we aimed to investigate the effects of BPV on development of any intracerebral hemorrhage $(\mathrm{ICH})$ and sICH and 3-month outcome after IVT in acute ischemic stroke.

\section{Methods}

From our consecutive local stroke database, we extracted data for all prospectively documented patients treated with recombinant tissue plasminogen activator intravenously in the years 2007-2009. Local standard operating procedures recommend BP to be measured using an automatic monitoring system (Infinity Delta, Draeger Medical Systems Inc.) before IVT, every 15 min for the first $2 \mathrm{~h}$ after the start of IVT and at least hourly thereafter until the follow-up imaging examination. Exceptions from this rule are patients with BP levels above $185 / 90 \mathrm{~mm} \mathrm{Hg}$ where these intervals are shortened. In case of elevated BP before and after IVT, treatment with antihypertensives - usually urapidil (5-50 mg i.v.) - is recommended in the standard operating procedures. BP levels are noted in the patient's file, which is electronically archived after discharge. These documents formed the basis for our retrospective analysis of the BP levels. Baseline and demographic characteristics, cardiovascular risk factors, time intervals, admission and follow-up imaging scans, and stroke severity using the NIHSS were prospectively collected. All patients were reassessed after 3 months either during an outpatient visit or by a telephone interview using the modified Rankin Scale by an investigator not blinded to the IVT treatment but unaware of BP levels and BPV. A favorable outcome after 3 months was defined as a modified Rankin Scale score of less than 2 .

Early infarct signs were defined as parenchymal hypoattenuation or loss of gray-white differentiation in the cortical ribbon or the basal ganglia and/or mass effect in the baseline CT due to an ischemic lesion.
A follow-up imaging scan was performed 20-36 h after IVT or immediately after clinical deterioration was diagnosed. If clinical deterioration developed later, another scan was carried out; thus, later clinically relevant bleedings were also detected and collected. New hyperdense brain lesions were counted as ICH, irrespective of the clinical consequences. According to the definition in the ECASS trials [14], the ICHs were grouped according to morphological appearance. HT was defined as a petechial infarction, whereas HT1 presents small and HT2 more confluent petechiae. Parenchymal hematoma ( $\mathrm{PH})$ contributes to a hemorrhage with mass effect. PH1 was defined as hemorrhage $\leq 30 \%$ of the infarcted area with mild space occupying effect and $\mathrm{PH} 2>30 \%$ of the infarcted area with significant space occupying effect, or clot remote from infarcted area. sICH was defined according to the ECASS 2 definition (detection of blood plus NIHSS worsening by 4 or more points or leading to death).

The BP values were analyzed until follow-up imaging scan and are described as follows: mean, maximum, minimum, standard deviation (SD) and difference between maximum and minimum. To represent BPV of an individual, we used successive variation (SV) and maximum SV [9]. SV is calculated as the square root of the average squared difference between two successive BP measurements using the following equation:

$$
S V=\sqrt{\frac{1}{n-1} \sum_{i=1}^{n-1}\left(X_{i+1}-X_{i}\right)^{2}}
$$

In contrast with the widely known sample SD, the SV addresses the time sequence of measurements. Patients were grouped in high ( $>$ median) and low ( $\leq$ median) systolic and diastolic BPV.

Due to the retrospective character of this study, the lack of treatment influence, and data being collected as part of national and international quality control programs, we did not apply for the vote of an ethics committee.

\section{Statistical Analysis}

Normally distributed data are present as mean and SD and nonnormally distributed data as median and interquartile range or counts and percentages, respectively. Comparison between $\mathrm{ICH}$-negative, ICH-positive and sICH according to baseline characteristics, risk factors for ICH and BP values as well as univariate analysis of outcome parameters were conducted with oneway ANOVA. All parameters showing significance in the univariate analysis were tested in a multivariate logistic regression model to explore predictors for ICH and main outcome parameters. Due to the possible colinearity of tested variables, we applied a stepwise logistic regression model. The results were considered statistically significant when $\mathrm{p}<0.05$. For all statistical testing, we used the Statistical Package for Social Sciences (SPSS Inc., v. 16.0 for Windows).

\section{Results}

Among 427 patients treated with IVT in the years 2007-2009, 51 (11.9\%) patients had any ICH and 10 (2.3\%) patients suffered from sICH. We observed HT1 in 14 (3.3\%), HT2 in 10 (2.3\%), $\mathrm{PH} 1$ in 16 (3.7\%), $\mathrm{PH} 2$ in 10 
Table 1. Univariate analyses of baseline characteristics

\begin{tabular}{lccccc}
\hline Parameter & $\begin{array}{l}\text { ICH negative } \\
(\mathrm{n}=376 ; 88.1 \%)\end{array}$ & $\begin{array}{l}\text { ICH positive } \\
(\mathrm{n}=51 ; 11.9 \%)\end{array}$ & $\mathrm{p}^{1}$ & $\begin{array}{l}\text { sICH } \\
(\mathrm{n}=10 ; 2.3 \%)\end{array}$ & $\mathrm{p}^{2}$ \\
\hline $\begin{array}{l}\text { Age, years } \\
\text { Female }\end{array}$ & $72.7 \pm 12.8$ & $73.2 \pm 11$ & 0.83 & $74.9 \pm 14.6$ & 0.59 \\
Risk factors & $195(51.8)$ & $25(49.0)$ & 0.70 & $8(80)$ & 0.08 \\
$\quad$ & & & & \\
$\quad$ Hypertension & $303(80.6)$ & $41(80.4)$ & 0.99 & $10(100)$ & 0.13 \\
$\quad$ Diabetes & $91(24.2)$ & $10(19.6)$ & 0.50 & $3(30)$ & 0.66 \\
Hypercholesterolemia & $92(24.5)$ & $13(25.5)$ & 0.85 & $3(30)$ & 0.68 \\
$\quad$ Atrial fibrillation & $123(32.7)$ & $24(47.1)$ & 0.041 & $5(50)$ & 0.25 \\
$\quad$ Nicotine use & $66(17.6)$ & $8(15.7)$ & 0.77 & $1(10)$ & 0.55 \\
Antiplatelet use & $163(43.4)$ & $24(47.1)$ & 0.64 & $5(50)$ & 0.48 \\
$\quad$ Anticoagulant use & $21(5.6)$ & $4(7.8)$ & 0.52 & 0 & 0.47 \\
Previous cardiovascular event & $61(16.2)$ & $10(19.6)$ & 0.52 & $4(40)$ & 0.05 \\
\hline
\end{tabular}

Figures are means $\pm \mathrm{SD}$ or numbers with percentages in parentheses. The figure in italics indicates statistical significance.

${ }^{1}$ One-way ANOVA. ${ }^{2}$ Comparison between no ICH and sICH.

(2.3\%) and subarachnoid hemorrhage in $1(0.3 \%)$ of our patients. Table 1 shows baseline characteristics and table 2 shows risk factors for any $\mathrm{ICH}$ and sICH and radiological ICH types. The median frequency (interquartile range) of BP measurements until follow-up imaging scan was 21.5 (9) in ICH-negative, 20 (9) in ICH-positive and 12.6 (15) in sICH patients.

Systolic and diastolic BP profiles, including mean, maximum, minimum, $\mathrm{SD}$, difference between maximum and minimum, SV and maximum SV did not differ between ICH-negative, ICH-positive and sICH patients (table 3), with the exception of the minimum diastolic BP, showing significantly higher levels in ICH-positive than $\mathrm{ICH}$-negative patients $(\mathrm{p}=0.02)$.

In univariate analysis of systolic and diastolic BP, each of them divided into groups of high and low BPV, we found an association between high systolic BPV and occurrence of $\mathrm{sICH}(\mathrm{p}=0.03)$. With regard to the 3-month outcome, low systolic BPV was strongly related to independency $(\mathrm{p}<0.001)$ and there was a trend of high systolic BPV being related to mortality $(\mathrm{p}=0.07)$. Mortality was more frequent in patients with high diastolic BPV $(p=0.04)$ and independency tended to appear more often in patients with low diastolic BPV ( $\mathrm{p}=$ 0.07) (table 4).

In a stepwise logistic regression model including all parameters showing a significant difference between $\mathrm{ICH}$-positive and $\mathrm{ICH}$-negative patients in univariate analysis (NIHSS on admission, early CT findings, plate- lets, atrial fibrillation), neither systolic nor diastolic BPV predicts ICH. Only early CT findings remain an independent risk factor for $\mathrm{ICH}$ in our patients (OR $=2.74,95 \%$ $\mathrm{CI}=1.47-5.11, \mathrm{p}<0.01)$ (table 5). Because early infarct signs were the only parameter which was associated with sICH in univariate analysis, no multivariate analysis was performed.

The logistic regression model for the 3-month outcome identified age $(\mathrm{OR}=0.96,95 \% \mathrm{CI}=0.94-0.97, \mathrm{p}<$ $0.001)$, NIHSS on admission $(\mathrm{OR}=0.84,95 \% \mathrm{CI}=0.80$ $0.87, \mathrm{p}<0.001), \mathrm{ICH}(\mathrm{OR}=0.29,95 \% \mathrm{CI}=0.13-0.66, \mathrm{p}<$ $0.01)$ and high systolic BPV $(\mathrm{OR}=1.68,95 \% \mathrm{CI}=1.05-$ $2.69, \mathrm{p}<0.05)$ as independently associated with poor outcome. Age $(\mathrm{OR}=1.08,95 \% \mathrm{CI}=1.05-1.12, \mathrm{p}<0.001)$, NIHSS on admission $(\mathrm{OR}=1.10,95 \% \mathrm{CI}=1.06-1.15, \mathrm{p}<$ $0.001)$ and $\mathrm{ICH}(\mathrm{OR}=2.88,95 \% \mathrm{CI}=1.43-5.80, \mathrm{p}<0.01)$, but neither high systolic nor high diastolic BPV predicted mortality within 3 months (table 6).

\section{Discussion}

In this retrospective analysis of 427 consecutive patients treated with IVT, we report BP measurements until follow-up imaging scan in a range of 21 measurements per patient. First of all, we found no difference between BP levels in ICH-negative and ICH-positive patients. In contrast to a recently published study, we also found no difference in BPV between $\mathrm{ICH}$-negative and $\mathrm{ICH}$-posi- 
Table 2. Risk factors for ICH and sICH

\begin{tabular}{|c|c|c|c|c|c|}
\hline Parameter & $\begin{array}{l}\text { ICH negative } \\
(\mathrm{n}=376 ; 88.1 \%)\end{array}$ & $\begin{array}{l}\text { ICH positive } \\
(\mathrm{n}=51 ; 11.9 \%)\end{array}$ & $\mathrm{p}^{1}$ & $\begin{array}{l}\mathrm{sICH}^{2} \\
(\mathrm{n}=10 ; 2.3 \%)\end{array}$ & $\mathrm{p}^{3}$ \\
\hline Early infarct signs on $\mathrm{CT}^{4}(\mathrm{n}=394)$ & $99(\mathrm{n}=348 ; 28.4 \%)$ & $24(\mathrm{n}=46 ; 52.2 \%)$ & 0.0011 & $6(n=10 ; 60 \%)$ & 0.018 \\
\hline Time window, $\min$ & $168.4(102.8)$ & $170.5(94.4)$ & 0.89 & $179.7(55.5)$ & 0.73 \\
\hline Congestive heart failure & $87(23.1 \%)$ & $18(35.3 \%)$ & 0.06 & $5(50 \%)$ & 0.05 \\
\hline Platelets, /nl & $263.5(95.6)$ & $233.3(62.4)$ & 0.028 & $246.7(73.3)$ & 0.58 \\
\hline Serum glucose, $\mathrm{mg} / \mathrm{dl}$ & $134.7(47.7)$ & $139.5(44.4)$ & 0.45 & $127.6(29.9)$ & 0.64 \\
\hline NIHSS on admission & $10.5(9)$ & $14(8)$ & 0.015 & $15.5(12)$ & 0.47 \\
\hline Latency to follow-up imaging scan, $\mathrm{h}$ & $20.6(7.3)$ & $21.3(7.6)$ & 0.42 & $9.7(18.7)$ & $<0.001$ \\
\hline Number of measured BP per patient & $21.5(9)$ & $20(9)$ & & $12.6(15)$ & \\
\hline $\mathrm{BP}$ intervention & $131(34.8 \%)$ & $21(41.2 \%)$ & 0.37 & $2(20 \%)$ & 0.33 \\
\hline \multicolumn{6}{|l|}{ ICH types } \\
\hline HT1 & & $14(3.3 \%)$ & & & \\
\hline HT2 & & $10(2.3 \%)$ & & & \\
\hline PH1 & & $16(3.7 \%)$ & & & \\
\hline $\mathrm{PH} 2$ & & $10(2.3 \%)$ & & & \\
\hline SAH & & $1(0.3 \%)$ & & & \\
\hline sICH & & $10(2.3 \%)^{2}$ & & & \\
\hline
\end{tabular}

Figures are mean with SD in parentheses or median with interquartile range in parentheses (see text) or numbers with percentages in parentheses. The figures in italics indicate statistical significance. SAH = Subarachnoid hemorrhage.

${ }^{1}$ One-way ANOVA. ${ }^{2}$ ECASS 2 definition. ${ }^{3}$ Comparison between ICH negative and sICH. ${ }^{4}$ Thirty-three patients were treated based on MRI.

Table 3. Systolic and diastolic BP values and comparison between ICH negative, positive and sICH

\begin{tabular}{|c|c|c|c|c|c|}
\hline Parameter & $\begin{array}{l}\text { ICH negative } \\
(\mathrm{n}=376)\end{array}$ & $\begin{array}{l}\text { ICH positive } \\
(\mathrm{n}=51)\end{array}$ & $\mathrm{p}^{1}$ & $\begin{array}{l}\text { sICH } \\
(n=10)\end{array}$ & $\mathrm{p}^{2}$ \\
\hline SBP mean, mm Hg & $147.21 \pm 16.52$ & $149.28 \pm 15.66$ & 0.40 & $151.33 \pm 17.45$ & 0.43 \\
\hline SBP max, mm Hg & $179.97 \pm 21.99$ & $180.76 \pm 20.16$ & 0.81 & $182.6 \pm 20.87$ & 0.71 \\
\hline $\mathrm{SBP} \min , \mathrm{mm} \mathrm{Hg}$ & $117.79 \pm 18.27$ & $120.88 \pm 18.83$ & 0.29 & $127 \pm 21.24$ & 0.12 \\
\hline SBP SD, mm Hg & $16.66 \pm 5.74$ & $16.6 \pm 5.79$ & 0.98 & $18.92 \pm 8.56$ & 0.21 \\
\hline SBP $\max -\min , \mathrm{mm} \mathrm{Hg}$ & $62.18 \pm 22.64$ & $59.88 \pm 22.6$ & 0.50 & $55.6 \pm 29.59$ & 0.60 \\
\hline SBP SV & $13.47 \pm 4.63$ & $14.28 \pm 5.51$ & 0.25 & $16.14 \pm 7.94$ & 0.08 \\
\hline SBP SV max, mm Hg & $40.89 \pm 15.99$ & $40.14 \pm 18.04$ & 0.75 & $41.2 \pm 23.64$ & 0.95 \\
\hline DBP mean, $\mathrm{mm} \mathrm{Hg}$ & $74.83 \pm 9.32$ & $77.41 \pm 9.29$ & 0.06 & $75.13 \pm 10.44$ & 0.92 \\
\hline DBP max, $\mathrm{mm} \mathrm{Hg}$ & $99.39 \pm 14.5$ & $100.37 \pm 12.02$ & 0.65 & $94.9 \pm 12.45$ & 0.33 \\
\hline DBP min, $\mathrm{mm} \mathrm{Hg}$ & $55.20 \pm 10.29$ & $58.82 \pm 10.89$ & 0.02 & $60.5 \pm 13.63$ & 0.11 \\
\hline DBP SD, mm Hg & $11.76 \pm 3.79$ & $12.09 \pm 4.06$ & 0.56 & $11.56 \pm 5.89$ & 0.87 \\
\hline $\mathrm{DBP} \max -\min , \mathrm{mm} \mathrm{Hg}$ & $44.19 \pm 15.33$ & $41.55 \pm 15.44$ & 0.25 & $34.4 \pm 19.65$ & 0.05 \\
\hline DBP SV, mm Hg & $9.52 \pm 2.92$ & $10.40 \pm 4.60$ & 0.06 & $10.41 \pm 7.11$ & 0.37 \\
\hline DBP SV max, mm Hg & $30.35 \pm 12.29$ & $30.67 \pm 12.39$ & 0.86 & $25.4 \pm 13.07$ & 0.21 \\
\hline
\end{tabular}

Figures are means \pm SD. The figures in italics indicate statistical significance. $\mathrm{SBP}=$ Systolic BP; $\mathrm{DBP}=$ diastolic $\mathrm{BP}$.

${ }^{1}$ One-way ANOVA. ${ }^{2}$ Comparison between ICH negative and sICH. 
Table 4. Univariate analysis of patients with high and low variability of systolic and diastolic BP and occurrence of HT and sICH and outcome parameters

\begin{tabular}{|c|c|c|c|c|c|c|}
\hline Parameter & $\begin{array}{l}\text { Systolic BP low } \\
\text { variability }^{3}(n=213)\end{array}$ & $\begin{array}{l}\text { Systolic BP high } \\
\text { variability }^{4}(\mathrm{n}=214)\end{array}$ & $\mathrm{p}^{5}$ & $\begin{array}{l}\text { Diastolic BP low } \\
\text { variability }^{3}(n=213)\end{array}$ & $\begin{array}{l}\text { Diastolic BP high } \\
\text { variability }^{4}(\mathrm{n}=214)\end{array}$ & $\mathrm{p}^{5}$ \\
\hline $\mathrm{HT}$ & $26(12.2 \%)$ & $25(11.7 \%)$ & 0.87 & $24(11.3 \%)$ & $27(12.6 \%)$ & 0.67 \\
\hline sICH & $3(1.4 \%)$ & $7(3.3 \%)$ & 0.03 & $4(1.9 \%)$ & $6(2.8 \%)$ & 0.53 \\
\hline Independency ${ }^{1}$ & $115(53.9 \%)$ & $79(36.9 \%)$ & $<0.001$ & $106(49.8 \%)$ & $88(41.1 \%)$ & 0.07 \\
\hline Mortality $^{2}$ & $35(16.4 \%)$ & $50(23.4)$ & 0.07 & $34(15.9 \%)$ & $51(23.8 \%)$ & 0.04 \\
\hline
\end{tabular}

The figures in italics indicate statistical significance.

${ }^{1}$ mRS score $\leq 2$ at day $90 .{ }^{2}$ mRS score $=6$ at day $90 .{ }^{3} \leq$ Median SD. ${ }^{4}>$ Median SD. ${ }^{5}$ One-way ANOVA.

Table 5. Final stepwise logistic regression model to predict any $\mathrm{ICH}$

\begin{tabular}{lll}
\hline Variable & Odds ratio $(95 \% \mathrm{CI})$ & $\mathrm{p}^{1}$ \\
\hline NIHSS & & 0.13 \\
Early CT findings & $2.74(1.47-5.11)$ & 0.002 \\
Atrial fibrillation & 0.06 \\
Platelets & 0.06 \\
Systolic BP low variability & 0.49 \\
\hline
\end{tabular}

${ }^{1}$ One-way ANOVA.

tive patients and therefore we cannot confirm a relation between BPV and development of ICH or sICH which was suggested in this study [12]. However, in agreement with Yong et al. [9], we report systolic BPV as a strong and independent predictor of the 3-month outcome after acute stroke and IVT.

There are some differences between our study and the study by Ko et al. [12] which might partially explain these discrepancies: the number of patients who received IVT was nearly three times higher in our study (427 vs. 158), although the absolute number of patients was smaller. We exclusively report about patients receiving IVT; this might explain why the absolute BP levels are lower due to a more aggressive treatment of elevated BP levels in those patients (e.g. maximum systolic $\mathrm{BP}$ in $\mathrm{ICH}$-positive patients 188.6 vs. $180.8 \mathrm{~mm} \mathrm{Hg}$, maximum diastolic BP in $\mathrm{ICH}$-negative patients 113.7 vs. $99.4 \mathrm{~mm} \mathrm{Hg}$ ). However, this does not explain why SD values of systolic and diastolic BP are remarkably similar, i.e. 16.5 and $11.2 \mathrm{~mm}$ $\mathrm{Hg}$ in the study by Ko et al. [12] and 16.7 and $11.8 \mathrm{~mm}$
Table 6. Final stepwise logistic regression model to predict main outcome parameters

\begin{tabular}{|c|c|c|c|c|}
\hline & \multicolumn{2}{|c|}{ Mortality at day $90^{\mathrm{a}}$} & \multicolumn{2}{|c|}{ Independency at day $90^{\mathrm{b}}$} \\
\hline & $\begin{array}{l}\text { odds ratio } \\
\text { (95\% CI) }\end{array}$ & $\mathrm{p}$ & $\begin{array}{l}\text { odds ratio } \\
(95 \% \text { CI })\end{array}$ & $\mathrm{p}$ \\
\hline Age & $\begin{array}{l}1.08 \\
(1.05-1.12)\end{array}$ & $<0.001$ & $\begin{array}{l}0.96 \\
(0.94-0.97)\end{array}$ & $<0.001$ \\
\hline NIHSS & $\begin{array}{l}1.10 \\
(1.06-1.15)\end{array}$ & $<0.001$ & $\begin{array}{l}0.84 \\
(0.80-0.87)\end{array}$ & $<0.001$ \\
\hline $\mathrm{ICH}$ & $\begin{array}{l}2.88 \\
(1.43-5.80)\end{array}$ & $<0.01$ & $\begin{array}{l}0.29 \\
(0.13-0.66)\end{array}$ & $<0.01$ \\
\hline $\begin{array}{l}\text { Diastolic BP } \\
\text { low variability }\end{array}$ & & n.s. & & \\
\hline $\begin{array}{l}\text { Systolic BP low } \\
\text { variability }\end{array}$ & & & $\begin{array}{l}1.68 \\
(1.05-2.69)\end{array}$ & $<0.05$ \\
\hline
\end{tabular}

${ }^{\mathrm{a}} \mathrm{mRS}$ score $=6 .{ }^{\mathrm{b}} \mathrm{mRS}$ score $\leq 2$.

$\mathrm{Hg}$ in ours. We observed $\mathrm{BP}$ values until control imaging scan - in a range of $24 \mathrm{~h}$ after admission - whereas Ko et al. [12] obtained BP measurements during the first $72 \mathrm{~h}$. During this period, our median frequency of BP measurements was 21 as compared with 18 and thus we monitored more BP levels in a shorter interval. Finally, in contrast to Ko et al. [12], we differentiate between radiologic types of ICH and especially between asymptomatic and symptomatic ones, because whether or not asymptomatic ICH is of any clinical relevance is still doubtful [15].

Pathophysiological considerations concerning the impact of BPV include that, on the one hand, a rapid increase in BP could lead to rupture of blood vessels and 
therefore to HT/ICH, and on the other hand a sudden decrease might cause a shortage of cerebral perfusion and thus could lead to a clinically relevant deterioration due to reduced perfusion of the penumbra.

All in all, it seems that low BPV is beneficial for longterm outcome and to counteract high BPV might be a target to improve outcome in IVT-treated stroke patients. But whether BPV leads to development of $\mathrm{ICH} / \mathrm{sICH}$ is still doubtful in our opinion, and thus the way BPV influences the outcome remains unclear.
As data from larger trials are still lacking due to the limited number of reported BP values, more data from single centers should be published to enable the performance of a meta-analysis in the future.

\section{Conclusion}

We demonstrate that high BPV in patients receiving IVT leads to poor outcome but does not increase the risk of $\mathrm{ICH} / \mathrm{sICH}$.

\section{References}

1 Larrue V, von Kummer R, Müller A, Bluhmki E: Risk factors for severe hemorrhagic transformation in ischemic stroke patients treated with recombinant tissue plasminogen activator: a secondary analysis of the European-Australasian Acute Stroke Study (ECASS II). Stroke 2001;32:438-441.

$\checkmark 2$ The National Institute of Neurological Disorders and Stroke rt-PA Study Group: Tissue plasminogen activator. N Engl J Med 1995; 333:1581-1587.

$\checkmark 3$ Hacke W, Kaste M, Fieschi C, Toni D, Lesaffre E, von Kummer R, Boysen G, Bluhmki E, Höxzer G, Mahagne MH, Hennerici M: Intravenous thrombolysis with recombinant tissue plasminogen activator for acute hemispheric stroke. The European Cooperative Acute Stroke Study (ECASS). JAMA 1995; 274:1017-1025.

-4 Tanne D, Kasner SE, Demchuk AM, KorenMorag N, Hanson S, Ground M, Levine SR: Markers of increased risk of intracerebral hemorrhage after intravenous recombinant tissue plasminogen activator therapy for acute ischemic stroke in clinical practice: the multicenter rt-PA Stroke Survey. Circulation 2002;105:1679-1685.

5 Demchuk AM, Morgenstern LB, Krieger DW, Linda Chi T, Hu W, Wein TH, Hardy RJ, Grotta JC, Buchan AM: Serum glucose level and diabetes predict tissue plasminogen activator-related intracerebral hemorrhage in acute ischemic stroke. Stroke 1999;30:34-39.
6 Hill MD, Buchan AM, Canadian Alteplase for Stroke Effectiveness Study (CASES) Investigators: Thrombolysis for acute ischemic stroke: results of the Canadian Alteplase for Stroke Effectiveness Study. CMAJ 2005; 172: 1307-1312.

7 Gilligan AK, Markus R, Read S, Srikanth V, Hirano T, Fitt G, Arends M, Chambers BR, Davis SM, Donnan GA, Australian Streptokinase Trial Investigators: Baseline blood pressure but not early computed tomography changes predicts major hemorrhage after streptokinase in acute ischemic stroke. Stroke 2002;33:2236-2242.

-8 Rothwell PM, Howard SC, Dolan E, O’Brian E, Dobson JE, Dahlöf B, Sever PS, Poulter NR: Prognostic significance of visit-to-visit variability, maximum systolic blood pressure, and episodic hypertension. Lancet 2010;375:895-905.

-9 Yong M, Diener HC, Kaste M, Mau J: Characteristics of blood pressure profiles as predictors of long-term outcome after acute ischemic stroke. Stroke 2005;36:2619-2625.

10 Yong M, Kaste M: Association of characteristics of blood pressure profiles and stroke outcomes in the ECASS-II trial. Stroke 2008; 39:366-372.

11 Delgado-Mederos R, Ribo M, Rubiera M, Munuera J, Santamarina E, Delgado P, Maisterra O, Alvarez-Sabin J, Molina CA: Prognostic significance of blood pressure variability after thrombolysis in acute stroke. Neurology 2008;71:552-558.
12 Ko Y, Park JH, Yang MH, Ko SB, Han MK, Oh CW, Lee J, Lee J, Bae HJ: The significance of blood pressure variability for the development of hemorrhagic transformation in acute ischemic stroke. Stroke 2010;41:25122518 .

13 Geeganage C, Tracy M, England T, Sare G, Moulin T, Woimant F, Christensen H, De Deyn PP, Leys D, O’Neill D, Ringelstein EB, Bath PM, for TAIST Investigators: Relationship between baseline blood pressure parameters (including mean pressure, pulse pressure, and variability) and early outcome after stroke: data from the Tinzaparin in Acute Ischaemic Stroke Trial (TAIST). Stroke 2011;42:491-493.

14 Hacke W, Kaste M, Fieschi C, von Kummer R, Davalos A, Meier D, Larrue V, Bluhmki E, Davis S, Donnan G, Schneider D, Diez-Tejedor E, Trouillas P: Randomised double-blind placebo-controlled trial of thrombolytic therapy with intravenous alteplase in acute ischaemic stroke (ECASS II). Second European-Australasian Acute Stroke Study Investigators. Lancet 1998;352:1245-1251.

15 Molina CA, Alvarez-Sabin J, Montaner J, Abilleira S, Arenillas JF, Coscojuela P, Romero F, Codina A: Thrombolysis-related hemorrhagic infarction: a marker of early reperfusion, reduced infarct size, and improved outcome in patients with proximal middle cerebral artery occlusion. Stroke 2002;33: 1446-1447. 